\title{
Roost fidelity in spectacled flying-foxes Pteropus conspicillatus: implications for conservation and management
}

\author{
Jennifer G Parsons', Simon KA Robson' and Louise A Shilton ${ }^{2}$ \\ ISchool of Marine and Tropical Biology, James Cook University, QId, 48II. \\ ${ }^{2}$ CSIRO, Sustainable Ecosystems, PO Box 780, Atherton, QId, 4883.
}

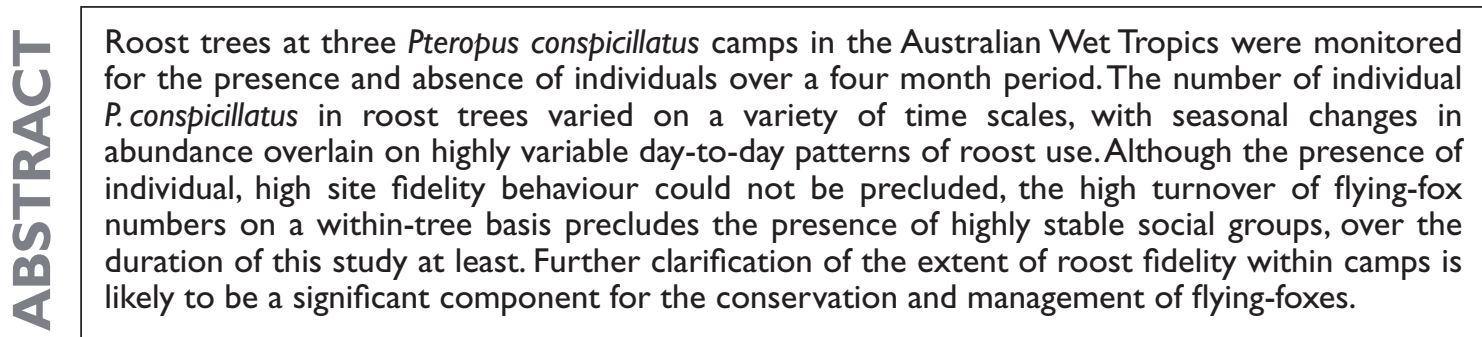

Key words: \#\#\#\#\#\#\#\#

\section{Introduction}

Flying-foxes are gregarious and they typically roost during the day in large numbers $(<10$ to hundreds of thousand individuals) in patches of trees within a wide range of vegetation types e.g. rainforest, mangroves, riparian and urban green-spaces (Tidemann et al. 1999, Vardon et al. 2001, Parsons et al. 2006, Williams et al. 2006). Knowledge of the roost fidelity of individual flying-foxes within a day-time camp has important implications for our understanding of their general biology, conservation and management. High roost fidelity opens the possibility of more stable social bonds between individuals with possible impacts on the development of social foraging and information transfer at roosts e.g. the spear nosed bat Phyllostomus hastatus (Wilkinson and Boughman 1998) and the evening bat Nycticeius bumeralis (Wilkinson 1992). Similarly, high roost fidelity (inferring limited mixing of individuals on a within-camp basis) could impact the methods used to census camp numbers, due to the nonrandom movement of individuals within a camp.

Unfortunately, monitoring the roosting position of flyingfoxes within a camp is difficult. Marking individuals is a time consuming and mostly invasive procedure and we do not yet have a solid understanding of the degree of individual site fidelity within camps. As part of a larger study into the diet of spectacled flying-foxes Pteropus conspicillatus (Parsons et al. 2006) we monitored the number of individual $P$. conspicillatus in specific trees at three camps in the Wet Tropics bioregion of North Queensland. In this paper, we analyse the level of flyingfox numbers in these trees over a four month period to infer patterns of individual tree-roost fidelity. Although this approach includes some limitations, because bats were not individually marked, the degree of changes in the numbers of individuals in particular tree

\section{Methods}

The numbers of flying-foxes roosting in 10 trees at each of three camps were recorded: two camps on the Atherton
Tablelands (Whiteing Road and Tolga Scrub) and one in the adjacent lowlands (at Gordonvale, Figure 1). The Atherton Tablelands is located in tropical North Queensland and consists of a complex mosaic of habitat types with large areas cleared for agriculture. This has created small rainforest fragments of varying plant composition that occur throughout the landscape.

Roosting trees were marked along a $50 \mathrm{~m}$ line transect (about $5 \mathrm{~m}$ apart), with the central roosting tree being located at the centre of the camp. These data were collected during the wet season between November 2004 and March 2005 , this time period included the peak of $P$. conspicillatus birthing (November and December). Records were taken every morning of the number and species of flying-foxes at selected roost trees using Pentax XCF 16x50 binoculars. The observer was situated at the base of the tree when recording bat numbers. The high canopy at one site (Whiteing Road) meant that observer presence did not disturb roosting bats and at the other two sites, numbers were only recorded once flying-foxes were habituated with observer presence. There was difficulty in observing gender of flying-foxes at Whiteing Road due to high canopy height, so this information was not recorded. Camp size estimates provided are from L.A. Shilton, P. Latch, A. McKeown and D. A. Westcott (unpublished data).

The Whiteing Road camp $\left(145^{\circ} 36.3^{\prime} \mathrm{E}, 17^{\circ} 33.36\right.$ 'S, at $760 \mathrm{~m}$ a.s.l.) is in a fragmented highland rainforest west of Milla Milla, surrounded by pastoral land. This is a seasonally occupied maternal camp used by both $P$. conspicillatus and P. scapulatus (little red flying-foxes). During this study, the numbers of $P$. conspicillatus fluctuated between 12,000 and 20,000 individuals. This camp was monitored for four months.

The Tolga Scrub camp $\left(145^{\circ} 28.8^{\prime} \mathrm{E}, 1^{\circ} 13.86\right.$ 'S, at 770 $\mathrm{m}$ a.s.l.) is located in a small and isolated fragment of Complex Notophyll Vine Forest Type 5b (Tracey 1982), outside the township of Atherton. Tolga Scrub is occupied by $P$. conspicillatus throughout the year (a permanent 
maternal roost), and numbers of $P$. conspicillatus fluctuated from 10,000 to 25,000 during the period of the study. Large numbers $(>100,000)$ of $P$. scapulatus were also present at this site during the study period. This camp was also monitored for four months.

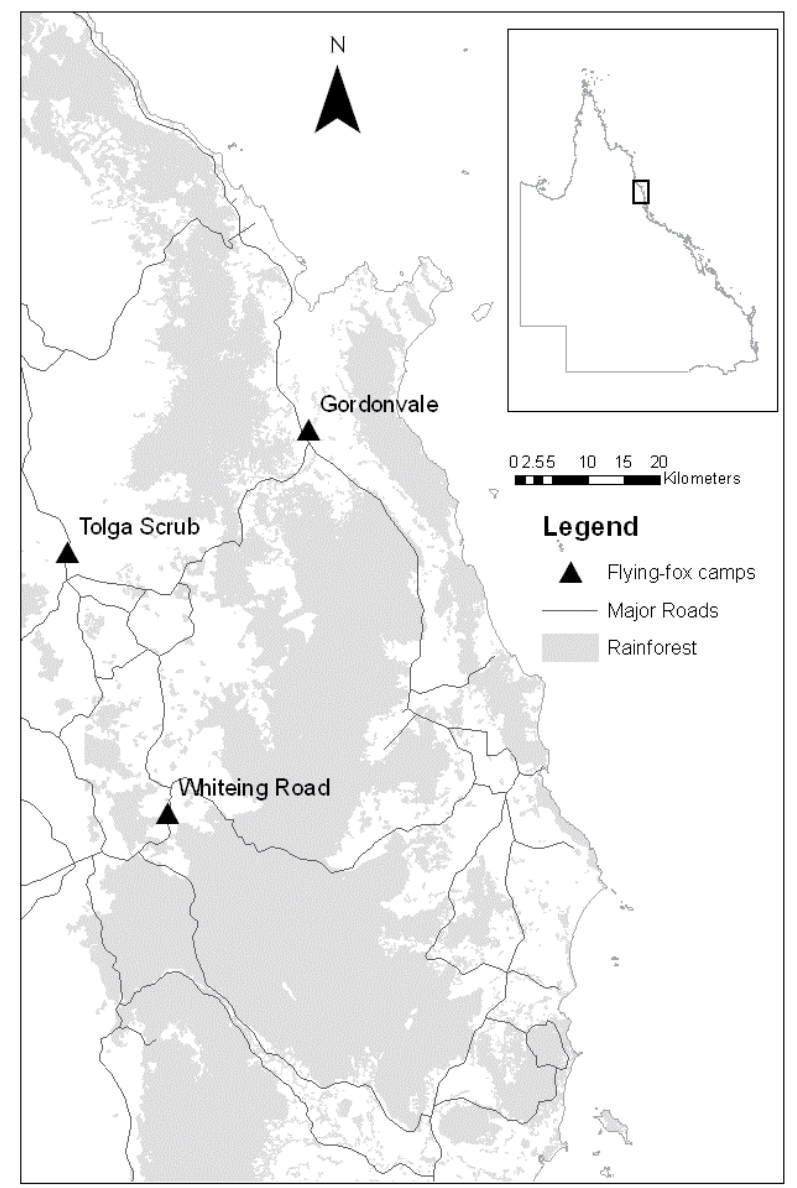

Figure I. Location of Spectacled Flying-fox camps surveyed in this study.

The Gordonvale camp $\left(145^{\circ} 46.74^{\prime} \mathrm{E}, 17^{\circ} 4.86 ' \mathrm{~S}\right.$, at $40 \mathrm{~m}$ a.s.l.) is in low to medium mixed shrubland and woodland with Melaleuca quinquinerva as the dominant species. It is surrounded by agricultural land (mainly sugarcane plantations) and suburban housing. This was the largest camp sampled, with over 40,000 $P$. conspicillatus present during this study. This is a permanent maternal camp. No other flying-fox species were sighted at the Gordonvale camp during this study. This camp was only monitored for two months (December and January).

\section{Results}

The number of flying-foxes in 10 trees in the Whiteing Road camp over a five day period in November are presented as a representative example of the overall pattern of tree use detected in this study (Figure 2). The pattern of flying fox numbers roosting within individual trees over time varied between trees, and different trees could display opposite trends. Over the five day period the total number of flying-foxes were relatively constant in Trees \#1, 2, 4 and 8, increased in Trees \#5 and 6, and decreased in Trees \#3, 9 and 10.
The pattern of tree use within a camp varies across trees, months and days (Figure 3), the number of flying-foxes roosting in each tree, organized by camp, day and month is shown. Agai n, significant differences between trees exist. The number of flying-foxes roosting in Tree \#5 in the Whiteing Road camp appears to be significantly higher in November than in the other months sampled, while the number of flying-foxes roosting in Trees \# 1, 2 and 3 appears similar across months.

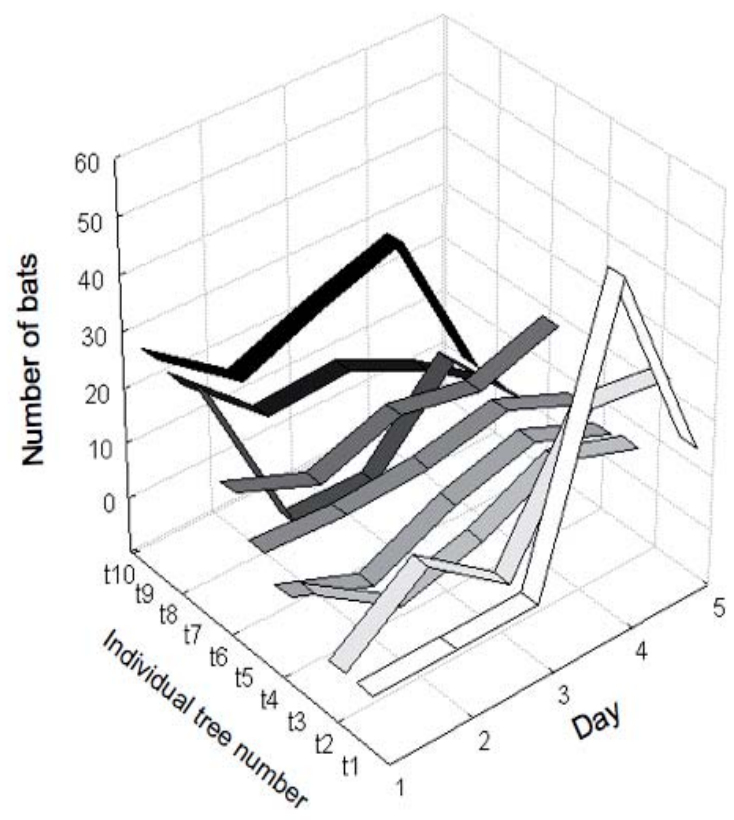

Figure 2. Evidence of extreme day to day variability in the number of flying-foxes roosting in ten individual trees at Whiteing Road flying-fox camp, November 2005.

The variation in roost number is represented by the coefficient of variation (CV) in the number of flying-foxes roosting in an individual tree over the five day census period (Figure 4). The $\mathrm{CV}$ is used to standardize the measure of variability by the number of flying-foxes occupying each tree. This frequency distribution indicates a high level of variability in the number of flying-foxes roosting in individual trees over the 5 day census periods, with the $\mathrm{CV}$ ranging from 0 to $223 \%$ $($ median $=72.5 \%)$.

\section{Discussion}

Pteropodids have been shown to display seasonal movements relating to food availability (Nelson 1965, Parry-Jones and Augee 1991, Spencer et al. 1991, Vardon and Tidemann 1999, Tidemann and Nelson 2004). While these movements traditionally relate to the availability of native fruit and blossom (Ratcliffe 1931, Eby 1991), it can also be influenced by the availability of non-traditional food sources such as planted non-native trees in urban environments (Parry-Jones and Augee 2001, Markus and Hall 2004). This consistent movement pattern between camps is also supported by molecular studies for Pteropus conspicillatus (Fox 2006) and for $P$. scapulatus (Sinclair et al. 1996) where a significant level of gene flow between camps has been demonstrated. Although Australian flying-foxes may use alternate camp 
sites at different times of the year, they do show high camp fidelity to traditional camps over longer time periods (Tidemann et al. 1999).

The results of our study suggest that the high, camp fidelity shown by Australian pteropodids is not matched by level of within-camp fidelity. The number of individual $P$. conspicillatus roosting within particular trees can vary significantly on a day-to-day basis. However it is worth noting that describing the behaviour of bats that are not individually marked does limit our ability to resolve patterns of roost site fidelity within a camp. A number on factors, such as temperature preferences, limiting predation and parasite loads and attempts to gain access for mating are likely to determine individual patterns of roost tree fidelity (Lewis 1995), but are difficult to assess in P. conspicillatus in the absence of knowledge of individual identities. Although the number of $P$. conspicallatus roosting in individual trees can vary on a day-to-day basis, some trees do contain a relatively constant number of bats over the five day period and it is possible that a small number of stable groups did exist. Resolving these relationships further represents a rich area of future research.

The number of flying-foxes at a camp at any given time is highly variable and it may be possible that our results simply reflect this temporal variation in camp size. It is possible that large influxes of bats to a camp would cause a redistribution of bats within particular trees seasonally. However, the high-degree of day to day variability at these camps suggests that this is not the only contributing factor to roost tree fidelity.

With bat species declining worldwide (Mickleburgh et al. 1992, Hutson et al. 2001) and two species of Australian

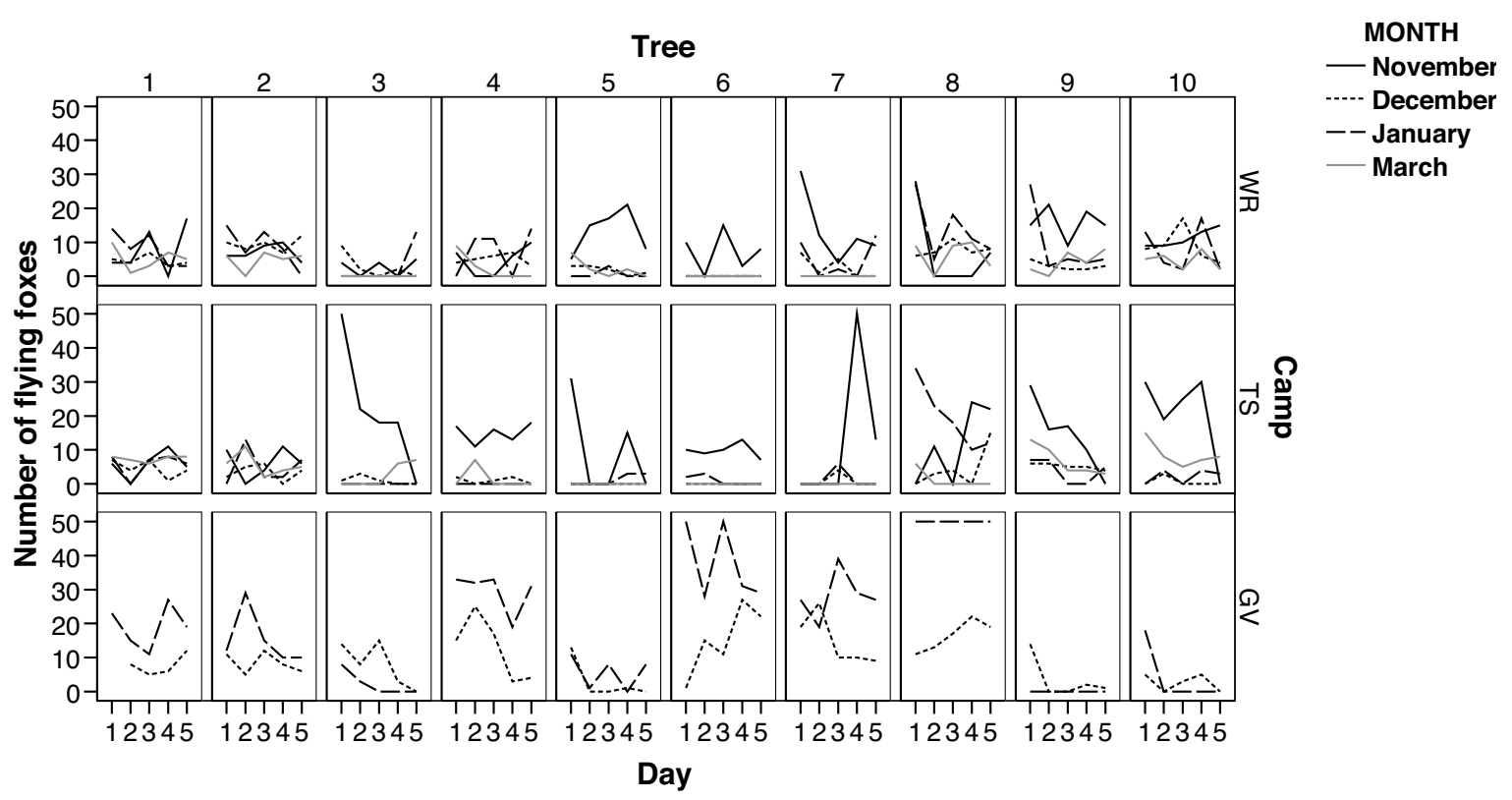

Figure 3. Variability of Pteropus conspicillatus numbers at ten roost trees in three camps recorded for five days over four months.

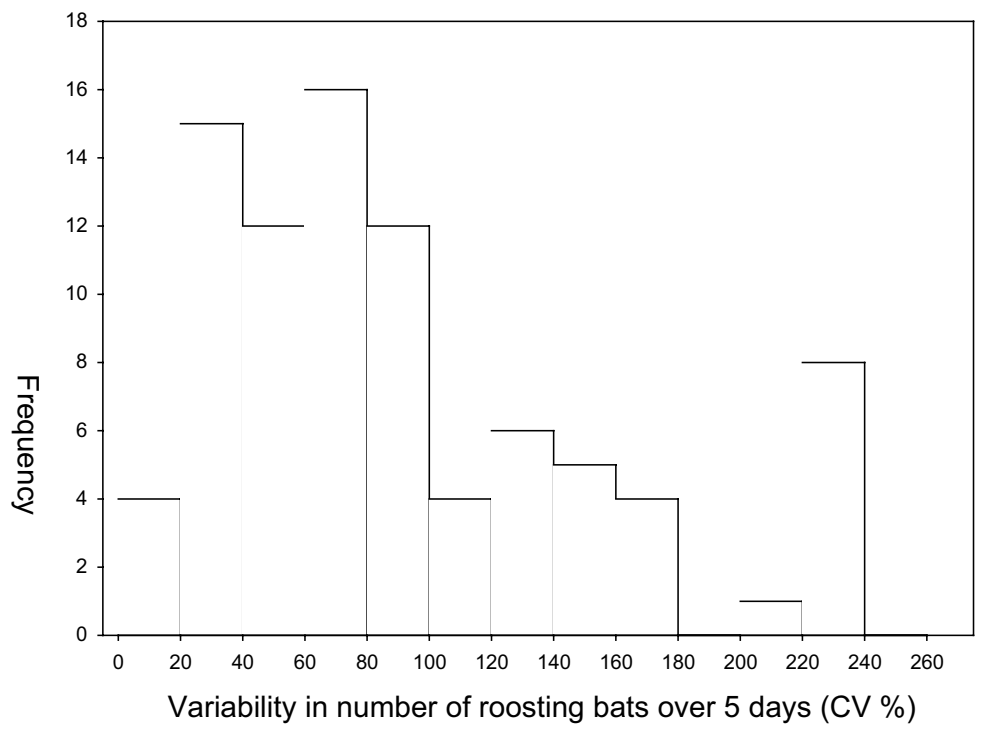

Figure 4. Within-tree variability in the number of roosting flying-foxes over a 5 day census period, as indicated by the coefficient of variation. 
flying fox, $P$. conspicillatus and $P$. poliocephalus listed as nationally threatened in 2001 and 2002 (Environment Protection and Biodiversity Conservation Act 1999), conservation strategies should address seasonal variations and internal variability in roosting habitats. Bats are important pollinators (Williams and Adam 1994, Tschapka 2004), dispersers of seed (Shilton et al. 1999, Hodgkison and Balding 2003) and other regenerative plant material (Parsons et al. 2007) which makes this decline a serious concern to the wider ecosystem. Many threats to roost trees and available camp sites, such as increased urbanisation, climate change and severe weather events are influencing the distribution and seasonal use of camps (Garnett et al. 1999, Parris and Hazell 2005, Parsons et al. unpublished data, Shilton et al. 2008). Preservation of existing roosts and knowledge of how these roosts are used is an important feature of flyingfox conservation. The information provided from this study indicates a significant variability in the roost fidelity of flying-foxes within individual trees within camps. Although the basis for these patterns remain uncertain the ecological and behavioural factors that underlie them are likely to significantly influence our management decisions. Developing methods to elucidate the dynamics of roost patters within individual camps remains an important challenge.

\section{Acknowledgements}

This study was financially supported by the Rainforest CRC and James Cook University. Advice and support was provided from A. Cairns, J. Maclean and Tolga Bat Research and Rescue.

\section{References}

Eby, P. 1991. Seasonal movements of Grey-headed flying foxes, Pteropus poliocephalus (Chiroptera:Pteropodidae), from two maternity camps in Northern New South Wales. Wildlife Research $18547-559$.

Fox, S. 2006. PhD Thesis. School of Marine and Tropical Biology, James Cook University.

Garnett, S., Whybird, O., and Spencer, H. 1999. The conservation status of the spectacled flying-fox Pteropus conspicillatus in Australia. Australian Zoologist 31: 38-54.

Hodgkison, R. and Balding, S.T. 2003. Fruit bats (Chiroptera: Pteropodidae) as seed dispersers and pollinators in a lowland Malaysian rainforest. Biotropica 35: 491-502.

Hutson, A.M., Mickleburgh, S. and Racey, P.A. 2001. 'Microchiropteran Bats: Global Status Survey and Conservation Action Plan'. International Union for Conservation of Nature and Natural Resources, Gland, Switzerland.

Lewis, S.E. 1995. Roost fidelity of bats: a review. Journal of Mammalogy 76: 481-496.

Markus, N. and Hall, L. 2004. Foraging behaviour of the black flying-fox (Pteropus alecto) in the urban landscape of Brisbane, Queensland. Wildlife Research 31: 345-355.

Mickleburgh, S., Racey, P.A., and Hutson, A.M. 1992. 'Old World Fruit Bat Action Plan'. International Union for Conservation of Nature and Natural Resources, Gland, Switzerland.

Nelson, J.E. 1965. Movements of Australian flying foxes (Pteropodidae: Megachiroptera). Australian Journal of Zoology 13: 53-73.

Parris, K.M., and Hazell, D.L. 2005. Biotic effects of climate change in urban environments: The case of the grey-headed flying fox (Pteropus poliocephalus) in Melbourne, Australia. Biological Conservation 124: 267-276.

Parry-Jones, K.A. and Augee, M.L. 1991. Food selection by grey-headed flying foxes (Pteropus poliocephalus) occupying a summer colony site near Gosford, New South Wales. Wildlife Research 18: 111-124.

Parry-Jones, K.A. and Augee, M.L. 2001. Factors affecting the occupation of a colony site in Sydney, New South Wales by the grey-headed flying fox Pteropus poliocephalus (Pteropodidae). Austral Ecology 26: 47-55.
Parsons, J.G., Cairns, A., Johnson, C.N., Robson, S.K.A., Shilton, L.A. and Westcott, D.A. 2006. Dietary variation in spectacled flying-foxes (Pteropus conspicillatus) of the Australian Wet Tropics. Australian Journal of Zoology 54: 417-428.

Parsons, J.G., Cairns, A., Johnson, C.N., Robson, S.K.A., Shilton, L.A. and Westcott, D.A. 2007. Bryophyte dispersal by flying foxes: a novel discovery. Oecologia 152: 112-114.

Ratcliffe, F.N. 1931. Notes on the fruit bats of Australia. Journal of Animal Ecology 1: 32-57.

Shilton, L.A., Altringham, J.D., Compton, S.G. and Whittaker, R.J. 1999. Old world fruit bats can be longdistance seed dispersers through extended retention of viable seeds in the gut. Proceedings of the Royal Society of London, Series B. 266: 219-223.

Shilton, L.A., Latch, P.J., McKeown, A., Pert, P. and Westcott, D.A. 2008. Landscape scale redistribution of a highly mobile threatened species, Pteropus conspicillatus (Chiroptera, Pteropodidae), in response to Tropical Cyclone Larry. Austral Ecology 33: 549-561.

Sinclair, E.A., Webb, N.J., Marchant, A.D. and Tidemann, C.R. 1996. Genetic variation in the little red flying fox Pteropus scapulatus (Chiroptera: Pteropodidae): implications for management. Biological Conservation 76: 45-50.

Spencer, H.J., Palmer, C. and Parry-Jones, K. 1991. Movements of fruit-bats in eastern Australia, determined by using radio-tracking. Wildlife Research 18: 463-468.

Tidemann, C.R. and Nelson, J.E. 2004. Long-distance movements of the grey-headed flying fox (Pteropus poliocephalus). Journal of Zoology 263: 141-146.

Tidemann, C.R., Vardon, M.J., Loughland, R.A. and Brocklehurst, P.J. 1999. Dry season camps of flying foxes (Pteropus spp.) in Kakadu World Heritage Area, north Australia. Journal of Zoology, London. 247: 155-163.

Tschapka, M. 2004. Energy density patterns of nectar resources permit coexistence within a guild of Neotropical flower-visiting bats. Journal of Zoology London 263, 7-21.

Vardon, M.J., Brocklehurst, P.S., Woinarski, J.C.Z., Cunningham, R.B., Donnelly, C.F. and Tidemann, C.R. 2001. Seasonal habitat use by flying-foxes, Pteropus alecto and $P$. scapulatus (Megachiroptera), in monsoonal Australia. Journal of Zoology 253: 523-535. 


\section{Roost fidelity in spectacled flying-foxes Pteropus conspicillatus}

Vardon, M.J. and Tidemann, C.R. 1999. Flying-foxes (Pteropus alecto and P. scapulatus) in the Darwin region, North Australia: patterns in camp size and structure. Australian Journal of Zoology 47: 411-423.

Wilkinson, G.S. 1992. Information transfer at evening bat colonies. Animal Behaviour 44: 501-518.

Wilkinson, G.S. and Boughman, J.W. 1998. Social calls coordinate foraging in greater spear-nosed bats. Animal Behaviour 55: 337-350.
Williams, G. and Adam, P. 1994. A review of rainforest pollination and plant-pollinator interactions with particular reference to Australian subtropical rainforests. Australian Zoologist 29: 177-212.

Williams, S.G., McDonnell, M.J., Phelan, G.K., Keim, L.D., and van der Ree, R. 2006. Range expansion due to urbanization: Increased food resources attract Grey-headed flying-foxes (Pteropus poliocephalus) to Melbourne. Austral Ecology 31: 190-198. 


\section{Appendix}
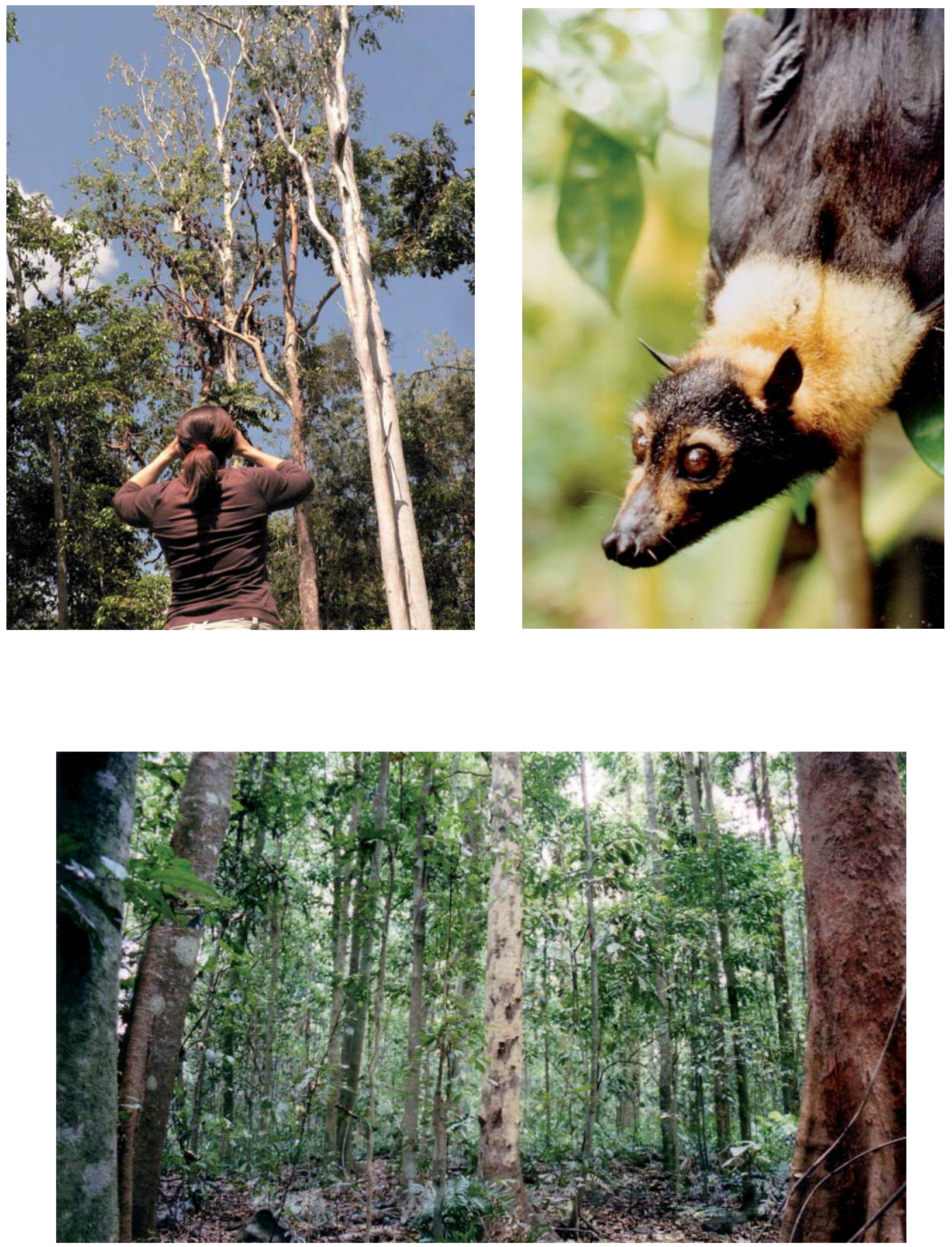